Archive for

Organic Chemistry

Arkivoc 2017, part iii, 151-165

\title{
Synthesis and antimitotic properties of ortho-substituted polymethoxydiarylazolopyrimidines
}

Natalia B. Chernyshova, ${ }^{a}$ Dmitry V. Tsyganov, ${ }^{a}$ Victor N. Khrustalev, ${ }^{b, c}$ Mikhail M. Raihstat, ${ }^{a}$ Leonid D. Konyushkin, ${ }^{a}$ Roman V. Semenov, ${ }^{a}$ Marina N. Semenova, ${ }^{d}$ and Victor V. Semenov*a

${ }^{a} N$. D. Zelinsky Institute of Organic Chemistry RAS, 47 Leninsky Prospect, 119991 Moscow, Russian Federation

${ }^{b}$ A. N. Nesmeyanov Institute of Organoelement Compounds, 28 Vavilov Street, 119991 Moscow, Russian

Federation

'Peoples' Friendship University of Russia (RUDN University), Moscow, Russian Federation

${ }^{d}$ N. K. Koltzov Institute of Developmental Biology RAS, 26 Vavilov Street, 119334 Moscow, Russian Federation

E-mail: vs@zelinsky.ru

\section{Dedicated to Professor Oleg A. Rakitin on the occasion of his 65th birthday}

Received 01-25-2017

Accepted 05-03-2017

Published on line 06-20-2017

\section{Abstract}

Ortho-substituted polymethoxydiarylazolopyrimidines were synthesized using polymethoxysubstituted benzaldehydes and acetophenones as starting material. X-ray crystallography data clearly confirmed that the subsequent cyclization of 3-amino-1,2,4-triazole with ketoaldehydes yielded polymethoxyphenylsubstituted 6,7-diaryl-[1,2,4]triazolo[1,5-a]pyrimidines as single isomers. All compounds were evaluated in vivo using phenotypic sea urchin embryo assay. 6-(4-Methoxyphenyl)-7-(3,4,5-trimethoxyphenyl)pyrazolo[1,5a]pyrimidine showed antimitotic microtubule destabilizing activity. The importance of aryl rings substituents in diaryltriazolopyrimidines for their antiproliferative antitubulin effect has been suggested.

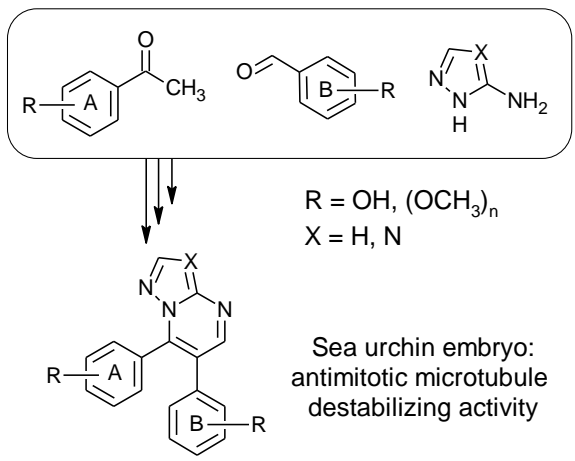

Keywords: Diarylazolopyrimidines, chalcone, sea urchin embryo, antimitotic, tubulin 


\section{Introduction}

The pyrimidine core, a building unit of DNA, RNA and nucleosides, can be found in a number of natural products representing pharmacologically attractive chemical scaffold. Various pyrimidine derivatives were reported to exhibit diverse biological activities including antimicrobial, ${ }^{1,2}$ antitubercular, ${ }^{3}$ antifungal, ${ }^{4}$ antiviral, $^{5}$ and antitumor effects. ${ }^{6,7}$ Notably, polymethoxysubstituted diarylpyrimidines displayed dual antimicrobial-anticancer properties. As an example, a pyrimidin-2-one (Figure 1, I) demonstrated antifungal activity against Candida albicans comparable with that of clotrimazole as well as inhibited growth of a panel of 60 human cancer cell lines with mean $\mathrm{GI}_{50}$, TGI and $\mathrm{LC}_{50}$ values of 3.39, 17.4, and 61.7 microMol, respectively. ${ }^{8}$<smiles>COc1ccc(C2=CC(c3cc(OC)c(OC)c(OC)c3)NC(=O)N2)cc1OC</smiles><smiles>COc1ccc(-c2ccccc2-c2cc(OC)c(OC)c(OC)c2)cc1O</smiles><smiles>COc1ccc(/C=C\c2cc(OC)c(OC)c(OC)c2)cc1O</smiles><smiles>[R]c1ccc(-c2cnc3ncnn3c2-c2ccccc2)cc1</smiles>

$\mathrm{R}^{1}, \mathrm{R}^{2}=\mathrm{Alk}, \mathrm{OMe}, \mathrm{Hal}, \mathrm{CF}_{3}$, etc.

Figure 1. Structures of polymethoxysubstituted diarylpyrimidines, combretastatin A-4 (II) and its heterocyclic derivatives.

Diarylpyrimidines can be considered as structural analogues of a potent natural antimitotic combretastatin A-4 (CA4, Figure 1, II) isolated from the bark of African willow tree Combretum caffrum. ${ }^{9}$ The cis-configuration of CA4 is essential for its antiproliferative antitubulin effect. Spontaneous isomerization to the trans-double bond observed both in vitro and in vivo causes a dramatic decrease of biological activity. ${ }^{10}$ To stabilize the active cis-conformation, several heteroaromatic rings, such as pyrazole, ${ }^{11}$ imidazole, ${ }^{11,12}$ thiazole, ${ }^{11}$ isoxazole, ${ }^{13,14} 1,2,3$-thiadiazole, ${ }^{15}$ isomeric triazoles, ${ }^{11,16,17}$ and tetrazole ${ }^{11,18-20}$ have been introduced as a nonisomerizable and metabolically stable isosteric equivalent of cis-double bond (Figure 1, III), resulting in highly active microtubule destabilizing antimitotic agents. Replacement of the double bond by triazolopyrimidine yielded diaryl-o-substituted-triazolopyrimidines (Figure 1, IV) with pronounced cytotoxicity against human cancer cells both in vitro and in mouse xenograft model. ${ }^{21}$ However, in contrast to CA4 derivatives III, these compounds promoted purified tubulin polymerization and stimulated aggregation of mitotic spindle microtubules in cells. ${ }^{21}$

For the design of potential anticancer molecules we synthesized a series of ortho-substituted polymethoxydiarylpyrimidines (Scheme 1, 7,8,9aa). 4-Methoxy, 3,4,5-trimethoxy, and 3-hydroxy-4-methoxy substituted aromatic aldehydes and ketones were used as starting material to prepare azolopyrimidines 
structurally similar to CA4 and its potent heterocyclic derivatives. The resulting compounds were evaluated for antimitotic activity in a sea urchin embryo model. Selected molecules were also screened against a panel of human cancer cell lines ( $\mathrm{NCl60}$ anticancer drug screen, http://dtp.cancer.gov).

\section{Results and Discussion}

Chemistry. Simple condensation of 3,4,5-trimethoxyacetophenone (1a) with 4-methoxybenzaldehyde (2a) resulted in chalcone 3aa (Scheme 1). Rearrangement of chalcone 3aa mediated by phenyliodine diacetate in the presence of $\mathrm{H}_{2} \mathrm{SO}_{4}$ afforded ketoaldehydediacetal 4aa in high yield, according to published procedure. ${ }^{22}$ Targeted diarylpyrimidines 7-9 were synthesized by condensation in acidic media of diacetal 4aa with the respective amines: urea, 3-aminopyrazole, or 3-amino-1,2,4-triazole. However, the yield of the desired products 7-9 was reduced by formation of byproducts 5 and $\mathbf{6}$. Small quantity of $\mathbf{5}$ and $\mathbf{6}$ were detected during the reaction by NMR-analysis and TLC. According to literature data, dimethylacetals (ex., 4aa) are easily deformylated to benzyl ketones in acidic ${ }^{22}$ and alkaline $e^{23}$ media. Pure benzyl ketone 6 was specially synthesized from dimethylacetal 4 aa in a quantitative yield.

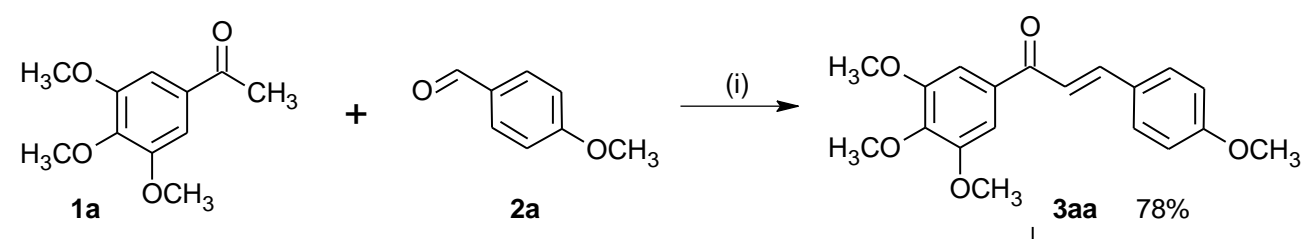<smiles>COc1ccc(-c2cnc(=O)[nH]c2-c2cc(OC)c(OC)c(OC)c2)cc1</smiles>

$\begin{array}{llll}74 \% & \mathrm{OCH}_{3}\end{array}$
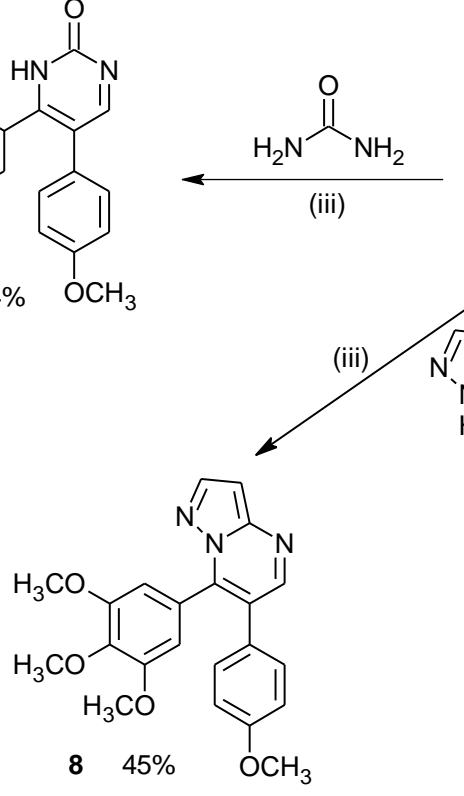

(ii)

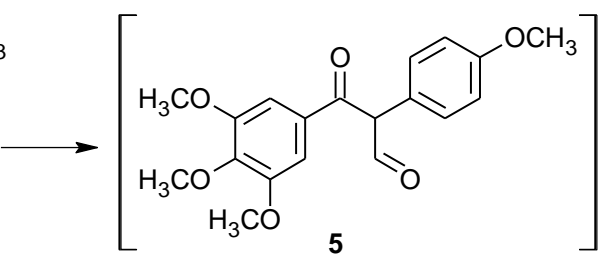

(iv)

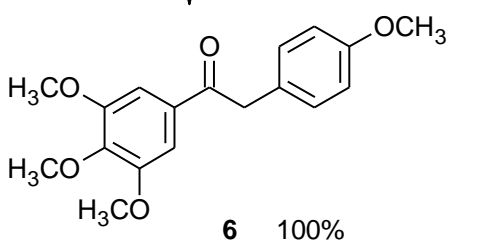

Scheme 1. Synthesis of diarylpyrimidines 7-9. Reagents and conditions: (i) NaOH-EtOH, rt, 24 h; (ii) Phl(OAc) 2 , $\mathrm{MeOH}-\mathrm{H}^{+}, \mathrm{rt}, 8$ h; (iii) EtOH-H+ ${ }^{+}$refux, 2-6.5 h; (iv) $\mathrm{KOH}-\mathrm{EtOH}$, reflux, 4 h.

Triazolopyrimidines $\mathbf{9 a b}$ and $\mathbf{9 b b}$ with 3-hydroxy-4-methoxybenzene ring were prepared from acetophenones $\mathbf{1} \mathbf{a}, \mathbf{b}$ and isovanillin (2b) (Scheme 2). Intermediate chalcones $\mathbf{3} \mathbf{a b}$ and $\mathbf{3 b} \mathbf{b}$ were acylated and rearranged to ketoacetals $\mathbf{4} \mathbf{a b}$ and $\mathbf{4} \mathbf{b b}$ accompanied by simultaneous removal of acetyl group. Further condensation of $\mathbf{4 a b}$ and $\mathbf{4 b}$ with 3-amino-1,2,4-triazole afforded targeted diarylazolopyrimidines 9 ab and 
9bb. Diarylazolopyrimidine 9ca derived from 3-acetoxy-4-methoxyacetophenone (1c) and anisaldehyde (2a) was synthesized from guaiacol (Scheme 3$).{ }^{24}$<smiles>[R]c1cc(C(C)=O)cc([R])c1OC</smiles>

1a: $\mathrm{R}=\mathrm{OCH}_{3}$

1b: $\mathrm{R}=\mathrm{H}$<smiles>[2H]c1cc(-c2c(-c3ccc(OC(C)(C)C)c(OC)c3)cnc3ncnn23)cc([2H])c1O</smiles><smiles>COc1ccc(C=O)cc1O</smiles>

2b Isovanillin

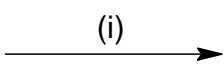<smiles>[2H]c1cc(C(=O)C(c2ccc(OC)c(O)c2)C(OC)OC)cc([2H])c1OC</smiles>

4ab in situ 70-80\%<smiles>[R]c1cc(C(=O)/C=C/c2ccc(OC)c(O)c2)cc([R])c1OC</smiles>

3ab: $\mathrm{R}=\mathrm{OCH}_{3} \quad 56-61 \%$ 3bb: $\mathrm{R}=\mathrm{H}$

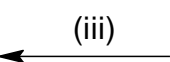<smiles>[R]c1cc(C(=O)/C=C/c2ccc(OC)c(OC(C)=O)c2)cc([2H])c1OC</smiles>

3ab-Ac $\quad 72-81 \%$ 3bb-Ac

Scheme 2. Synthetic route for preparation of compounds $\mathbf{9 a b}$ and $\mathbf{9 b b}$. Reagents and conditions: (i) $\mathrm{NaOH}-$ $\mathrm{EtOH}, \mathrm{rt}, 24 \mathrm{~h}$; (ii) AcCl-Pyridine, $\mathrm{CH}_{2} \mathrm{Cl}_{2}$, rt, 3 h; (iii) Phl(OAc) $2, \mathrm{MeOH}-\mathrm{H}^{+}, \mathrm{rt}, 8 \mathrm{~h}$; (iv) EtOH-H $\mathrm{H}^{+}$, reflux, 5 h.<smiles>COc1ccc(/C=C/C(=O)c2cc(/C=C/C(=O)c3ccc(OC)c(OC(C)=O)c3)ccc2OC)cc1OC(C)=O</smiles>

Scheme 3. Preparation of compound 9ca from guaiacol. Reagents and conditions: (i) $\mathrm{NaOH}-\mathrm{EtOH}, \mathrm{rt}, 24 \mathrm{~h}$; (ii) AcCl-Pyridine, $\mathrm{CH}_{2} \mathrm{Cl}_{2}$, rt, 3 h; (iii) $\mathrm{Phl}(\mathrm{OAc})_{2}, \mathrm{MeOH}-\mathrm{H}^{+}$, rt, 8 h; (iv) EtOH-H $\mathrm{H}^{+}$, reflux, 5 h.

Generally, during the reaction between 3-amino-1,2,4-triazoles and aliphatic ketoaldehydes (or their derivatives) cyclization can proceed in four different ways (Scheme 4). 


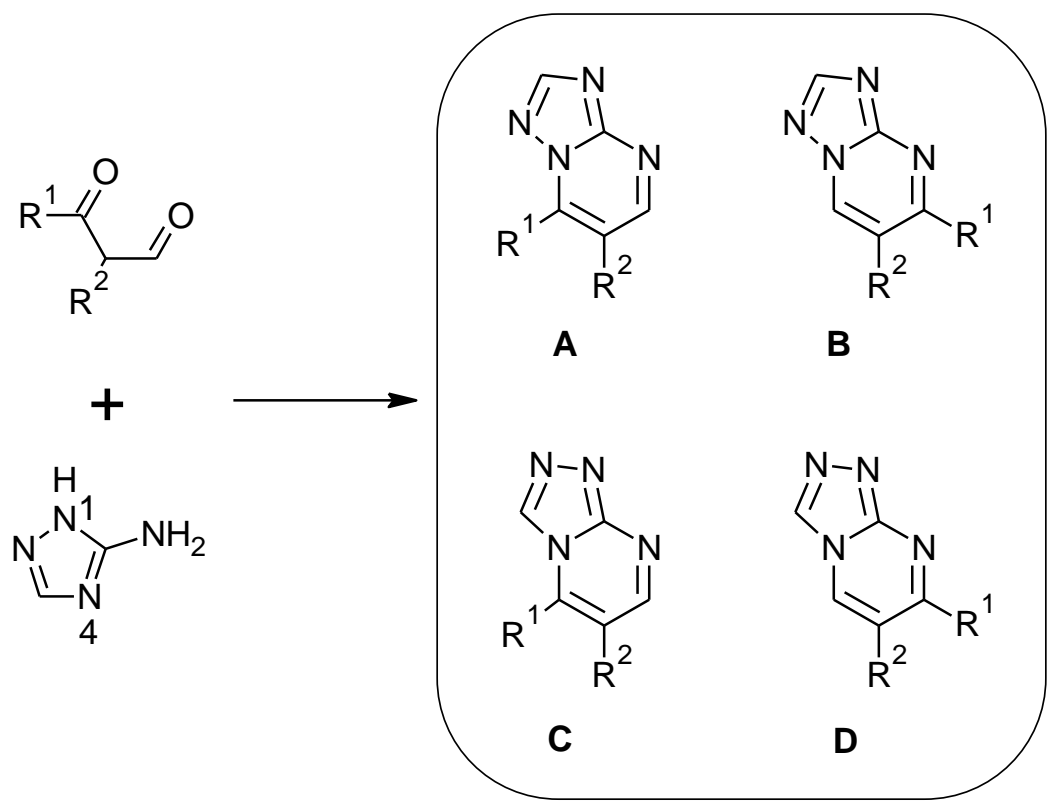

Scheme 4. Isomeric triazolopyrimidines which could be formed during condensation of ketoaldehydes with 3amino-1,2,4-triazole.

Type A: Connection of the aldehyde group with the amino group and of the ketone moiety with $\mathrm{N} 1$ atom. ${ }^{25}$ Type B: Coupling of the aldehyde group with N1 atom and of the ketone moiety with the amino group. ${ }^{26-28}$ Type C: Binding of the aldehyde group with the amino group and of the ketone moiety with N4 atom. Up to date, there are no literature data on the formation of a pure type $C$ isomer.

Type D: Connection of the aldehyde group with $\mathrm{N} 4$ atom and of the ketone moiety with the amino group. ${ }^{28}$ The formation of mixtures of two isomers $A+B^{26,27}$ or $A+C^{29}$ was published as well. Only two examples of diarylketoaldehydes cyclization with 3-amino-1,2,4-triazoles that proceeded according to type $A^{21,27}$ or $D^{30}$ have been reported.

X-ray structure determination. Literature data ${ }^{25-30}$ together with our results suggest that the structure of key pyrimidine products 9 could not be unambiguously confirmed by NMR analysis. In the present study X-ray crystallography was carried out in order to determine the precise structure of 6-(4-methoxyphenyl)-7-(3,4,5trimethoxyphenyl) $[1,2,4]$ triazolo[1,5-a]pyrimidine (9aa). The analysis confirmed type A cyclization with the formation of compound 9aa as isomer A (Figure 2).

The yellow prismatic crystal of 9 aa $\left(\mathrm{C}_{21} \mathrm{H}_{20} \mathrm{~N}_{4} \mathrm{O}_{4}, M=392.41\right)$ was triclinic, space group, $P-1$, at $T=120 \mathrm{~K}: a$ $=11.0658(7) \AA, b=12.6659(8) \AA, c=13.8403(9) \AA, \alpha=94.490(1)^{\circ}, b=101.040(1)^{\circ}, \gamma=90.963(1)^{\circ}, V=$ 1897.1(2) $\AA^{3}, Z=4, d_{\text {calc }}=1.374 \mathrm{~g} / \mathrm{cm}^{3}, F(000)=824, \mu=0.097 \mathrm{~mm}^{-1} .25375$ total reflections (11062 unique reflections, $\left.R_{\text {int }}=0.040\right)$ were measured on a three-circle Bruker APEX II CCD diffractometer $\left(\lambda\left(\operatorname{MoK}_{\alpha}\right)\right.$ radiation, graphite monochromator, $\varphi$ and $\omega$ scan mode, $2 \vartheta_{\max }=60.0^{\circ}$ ) and corrected for absorption. ${ }^{31}$ The structure was solved by direct methods and refined by a full-matrix least squares technique on $F^{2}$ with anisotropic displacement parameters for non-hydrogen atoms. One of the eight methoxy groups was disordered over two sites with the occupancies of 0.8:0.2. The hydrogen atoms were placed in calculated positions and refined within the riding model with fixed isotropic displacement parameters $\left(U_{\text {iso }}(H)=1.5 U_{\text {eq }}(C)\right.$ for the $\mathrm{CH}_{3}$-group and $U_{\text {iso }}(\mathrm{H})=1.2 U_{\text {eq }}(\mathrm{C})$ for the other groups). The final divergence factors were $R_{1}=0.049$ for 7812 independent reflections with $I>2 \sigma(I)$ and $w R_{2}=0.132$ for all independent reflections, $S=1.010$. All 
calculations were carried out using the SHELXTL program. ${ }^{32}$ Full crystallographic data for compound 9aa (Tables S1-S6, Supplementary Material) have been deposited with the Cambridge Crystallographic Data Center, CCDC 1525158. Copies of this information may be obtained free of charge from the Director, CCDC, 12 Union Road, Cambridge CB2 1EZ, UK. ${ }^{33}$

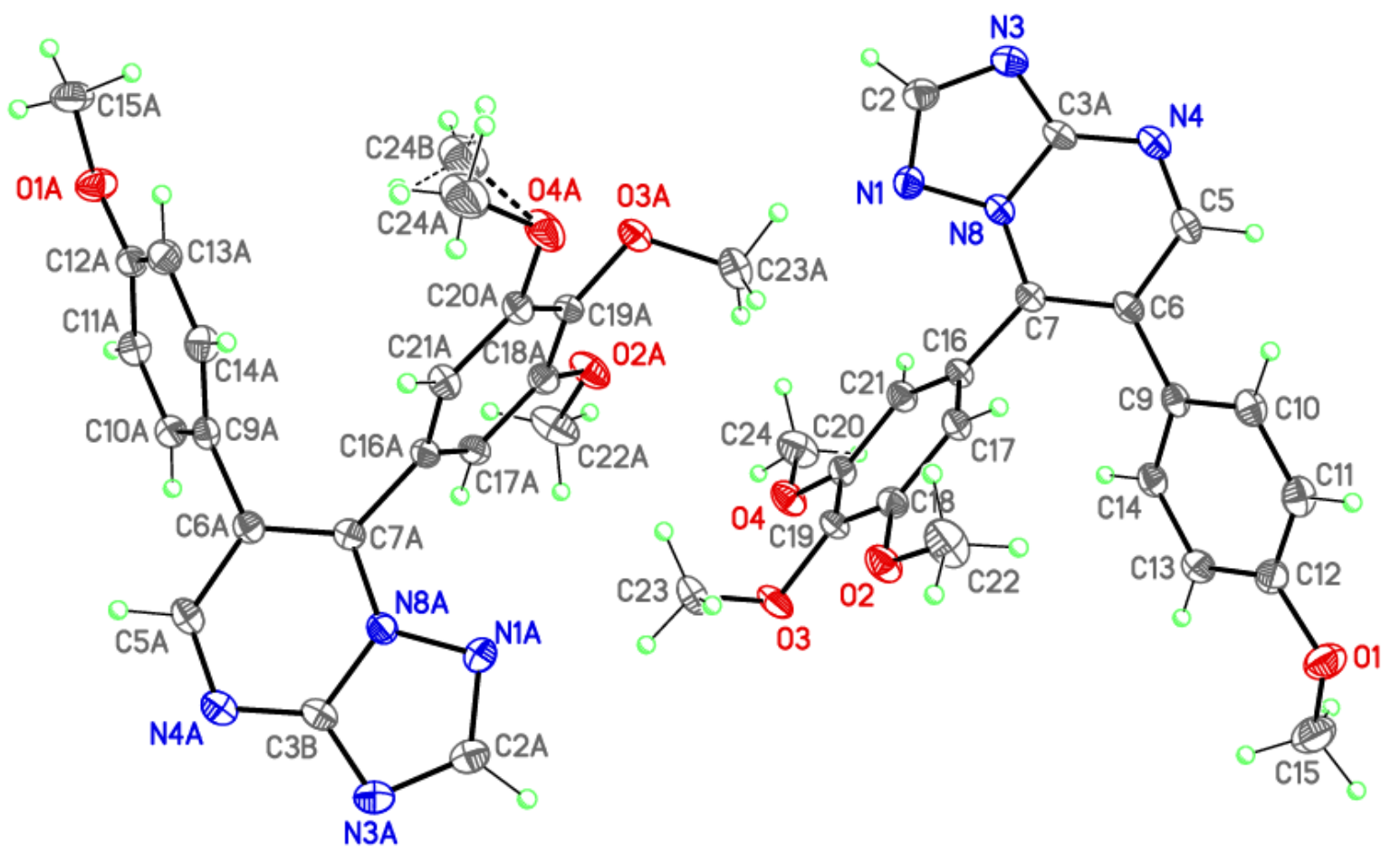

Figure 2. Molecular structure of 6-(4-methoxyphenyl)-7-(3,4,5-trimethoxyphenyl)[1,2,4]triazolo[1,5a]pyrimidine (9aa) (isomer A). Two crystallographically independent molecules distinguished by the conformations of methoxy groups are shown. The alternative position of the disordered methoxy group is depicted by dashed lines. Selected geometrical parameters ( $\AA$ and deg.): N1-C2 1.3286(17), N1-N8 1.3694(15), C2-N3 1.3562(18), N3-C3A 1.3363(18), C3A-N4 1.3452(17), C3A-N8 1.3859(16), N4-C5 1.3165(18), C5-C6 1.4305(17), C6-C7 1.3824(18), C7-N8 1.3668(16), C2-N1-N8 101.29(11), N1-C2-N3 117.29(13), C3A-N3-C2 102.27(11), N3-C3A-N4 128.76(12), N3-C3A-N8 109.47(11), N4-C3A-N8 121.77(12), C5-N4-C3A 115.67(11), N4-C5-C6 125.67(12), C5-C6-C7 117.65(12), N8-C7-C6 115.97(11) (Supplementary Material).

Biological evaluation. The targeted diarylazolopyrimidines 7-9 and by-product 6 were evaluated for antimitotic activity in a phenotypic sea urchin embryo assay. ${ }^{34}$ The assay provides rapid information on antiproliferative, embryotoxic, and microtubule destabilizing activities of tested molecules. The results are presented in Table 1 with CA4 as a positive control. For comparison, EC and $\mathrm{Gl}_{50}$ values for intermediate chalcones $\mathbf{3 a a}, \mathbf{3} \mathbf{a b}, \mathbf{3 d}$, and $\mathbf{3 e}$ were included. Compounds $\mathbf{3 d}$ and $\mathbf{3 e}$ were synthesized as described in the Experimental Section. 
Table 1. Effects of diarylazolopyrimidines on sea urchin embryos and human cancer cells<smiles>COc1ccc(C(=O)/C=C/c2cc(OC)c(OC)c(OC)c2)cc1</smiles><smiles>COc1ccc(C(=O)/C=C/c2cc(OC)c(OC)c(OC)c2)cc1O</smiles>

\begin{tabular}{|c|c|c|c|c|}
\hline \multirow[t]{2}{*}{ Compound } & \multicolumn{3}{|c|}{ Sea urchin embryo effects, EC (microMol) ${ }^{a}$} & \multirow{2}{*}{$\begin{array}{l}\text { Cell growth inhibition } \\
\mathrm{GI}_{50} \text { (microMol) }^{\mathrm{b}}\end{array}$} \\
\hline & $\begin{array}{l}\text { Cleavage } \\
\text { alteration }\end{array}$ & $\begin{array}{c}\text { Cleavage } \\
\text { arrest }\end{array}$ & $\begin{array}{l}\text { Embryo } \\
\text { spinning }\end{array}$ & \\
\hline $3 a a^{c}$ & 0.2 & $1(\mathrm{TE})^{\mathrm{d}}$ & $>5$ & $0.3(\mathrm{~K} 562)^{\mathrm{e}}$ \\
\hline $3 a b^{c}$ & 0.02 & $0.2(T E)^{d}$ & 0.5 & $0.0043(\mathrm{~K} 562)^{\mathrm{e}}$ \\
\hline $3 d^{c}$ & 2 & $>4$ & $>4$ & $4.5(\mathrm{~K} 562)^{\mathrm{e}}$ \\
\hline $3 e$ & 4 & $>4$ & $>4$ & $N D^{f}$ \\
\hline 6 & 4 & $>4$ & $>4$ & $N D^{f}$ \\
\hline 7 & 4 & $>4$ & $>4$ & $N D^{f}$ \\
\hline 8 & 0.5 & $4(T E)^{d}$ & $>5$ & $4.07^{g}$ \\
\hline 9aa & $>4$ & $>4$ & $>4$ & $>10$ \\
\hline $9 a b$ & $>4$ & $>4$ & $>4$ & $N D^{f}$ \\
\hline $9 b b$ & $>4$ & $>4$ & $>4$ & $N D^{f}$ \\
\hline $9 c a$ & $>4$ & $>4$ & $>4$ & $N D^{f}$ \\
\hline CA4 & 0.002 & 0.01 & 0.05 & $0.00768^{h}$ \\
\hline
\end{tabular}

${ }^{a}$ The sea urchin embryo assay was conducted as described previously. ${ }^{34}$ Fertilized eggs and hatched blastulae were exposed to 2 -fold decreasing concentrations of compounds. Duplicate measurements showed no differences in effective threshold concentration (EC) values.

$\left.{ }^{\mathrm{b}} \mathrm{G}\right|_{50}$ : concentration required for $50 \%$ cell growth inhibition.

${ }^{\mathrm{c}} \mathrm{EC}$ values from Ref. 35.

${ }^{d}$ TE: tuberculate eggs typical of microtubule destabilizing agents.

${ }^{\text {e }}$ Data from Ref. 36 for K562 human leukemia cell line.

${ }^{f} \mathrm{ND}$ : not determined.

$\mathrm{g}$ Mean value for 60 human cancer cell lines.

${ }^{\mathrm{h}}$ Mean value for 60 human cancer cell lines, NSC 613729.

As shown from Table 1, intermediate chalcones $3 a a$ and $3 a b$ exhibited antimitotic activity in the sea urchin embryo assay. Embryo spinning after the exposure to 3ab, a full analog of CA4, and tuberculate eggs characteristic for 3aa suggested their microtubule destabilizing mode of action. Notably, the interchange of substituted aryl rings in chalcones $\mathbf{3} \mathbf{a a}$ and $\mathbf{3} \mathbf{a b}$ yielded significantly less active compounds $\mathbf{3 d}$ and $\mathbf{3 e}$, respectively. Therefore we paid attention to the synthesis of azolopyrimidine isomers $\mathbf{8}$, 9aa, and 9 ab from intermediate chalcones $\mathbf{3 a a}$ and $\mathbf{3} \mathbf{a b}$. Cyclization of chalcones $\mathbf{3}$ into dyarylazolopyrimidines $\mathbf{8}$ and $\mathbf{9}$ resulted in decrease of antimitotic effect. Only pyrazolopyrimidine $\mathbf{8}$ exhibited antiproliferative and cytotoxic effects both in sea urchin embryos and human cancer cells. Compound $\mathbf{8}$ could be considered as microtubule targeting agent since it caused formation of tuberculate arrested eggs typical for microtubule destabilizers. In contrast 
to microtubule stabilizing diaryl-o-substituted-triazolopyrimidines (Figure $1, \mathbf{I V}){ }^{21}$ the antimitotic effect of pyrazolopyrimidine $\mathbf{8}$ was likely associated with microtubule disassembly. Pyrimidine derivative $\mathbf{7}$ as well as by-product 6 displayed weak antiproliferative activity. All four triazolopyrimidines 9 failed to affect cell division (cleavage) up to 4 microMol concentration. Generally, introduction of N-containing 5-membered heterocycles as linkers between two aryl rings in CA4 analogues (Figure 1, III) resulted in potent cytotoxic compounds with antimitotic microtubule destabilizing mode of action. ${ }^{11-20}$ Similarly, CA4 analogues with bicyclic triazolopyrimidine linker, halogen substituted triazolopyrimidines (Figure 1, IV), displayed cytotoxicity against human cancer cell lines with $\mathrm{IC}_{50}$ in nanomolar concentration range. ${ }^{21}$ In the present study, polymethoxyhydroxy-substituted diaryltriazolopyrimidines 9 were found to be inactive up to 4 microMol concentration. The results indicated the importance of aryl rings substituents in diaryltriazolopyrimidine derivatives of CA4 for their antimitotic antitubulin effects.

\section{Conclusions}

Ortho-substituted polymethoxydiarylazolopyrimidines were synthesized using condensation of polymethoxysubstituted benzaldehydes and acetophenones. Further cyclization of 3-amino-1,2,4-triazoles with aliphatic ketoaldehydes yielded triazolopyrimidines 9 as a single set of isomers. X-ray crystallography analysis exemplified by 6-(4-methoxyphenyl)-7-(3,4,5-trimethoxyphenyl)[1,2,4]triazolo[1,5-a]pyrimidine (9aa) confirmed that the cyclization of 3-amino-1,2,4-triazole with ketoaldehyde followed the reaction route to isomer A. Sea urchin embryo screen identified pyrazolopyrimidine $\mathbf{8}$ as antimitotic microtubule destabilizing agent, whereas diaryltriazolopyrimidines $\mathbf{9}$ were inactive. Aryl rings substituents in triazolopyrimidine analogues of CA4 are likely crucial for their antiproliferative antitubulin efficiency.

\section{Experimental Section}

General. Melting points were measured on a Boetius melting point apparatus and were uncorrected. Reaction mixtures were stirred magnetically. ${ }^{1} \mathrm{H}$ NMR spectra were recorded on a Bruker DRX-500 $(500.13 \mathrm{MHz})$ instrument. Chemical shifts were stated in parts per million (ppm) and referenced to the appropriate NMR solvent peak(s). Spin-spin coupling constants $(J)$ were reported in hertz $(\mathrm{Hz})$. Original ${ }^{1} \mathrm{H}$ NMR spectra for azolopyrimidines 7, 8, and $\mathbf{9}$ are presented in Supplementary Material. Low resolution mass spectra $(\mathrm{m} / \mathrm{z})$ were recorded on a Finnigan MAT/INCOS 50 mass spectrometer at $70 \mathrm{eV}$ using direct probe injection. Elemental analysis was performed on the automated PerkinElmer $2400 \mathrm{CHN}$ microanalyzer. Flash chromatography was carried out on silica gel (Acros $0.035-0.070 \mathrm{~mm}, 60 \AA$ ). TLC was performed on Merck 60 $\mathrm{F}_{254}$ plates.

General procedure for the synthesis of chalcones $3 .{ }^{37} \mathrm{NaOH}(60 \mathrm{mmol})$ was added to a vigorously stirred solution containing arylacetophenones $1(20 \mathrm{mmol})$ and benzaldehydes $2(20 \mathrm{mmol})$ in EtOH $(150 \mathrm{~mL})$ at $5{ }^{\circ} \mathrm{C}$. The reaction mixture was stirred at room temperature for $24 \mathrm{~h}$ and the solvent was evaporated. The residue was diluted with water $(130 \mathrm{~mL})$, neutralized with $15 \% \mathrm{HCl}$, and extracted with $\mathrm{CH}_{2} \mathrm{Cl}_{2}(3 \times 80 \mathrm{~mL})$. Organic extracts were washed with brine $(2 \times 80 \mathrm{~mL})$, dried with $\mathrm{Na}_{2} \mathrm{SO}_{4}$, and evaporated. The residue was crystallized from EtOAc-petroleum (1:1) and dried to afford chalcones 3. 
(2E)-3-(4-Methoxyphenyl)-1-(3,4,5-trimethoxyphenyl)-2-propen-1-one (3aa). Bright yellow crystals; Yield 5.12 g, 78\%; mp 99-101 ${ }^{\circ} \mathrm{C}$ (Lit. $\left.{ }^{38} 100-101{ }^{\circ} \mathrm{C}\right) ;{ }^{1} \mathrm{H}$ NMR (DMSO-d 6 ): $\delta 7.88\left(2 \mathrm{H}, \mathrm{d}, J 8.8 \mathrm{~Hz}, \mathrm{H}-2^{\prime \prime}, 6\right.$ "), 7.81 (1H, d, J $15.5 \mathrm{~Hz}, \mathrm{H}-2), 7.72(1 \mathrm{H}, \mathrm{d}, J 15.5 \mathrm{~Hz}, \mathrm{H}-3), 7.42\left(2 \mathrm{H}, \mathrm{s}, \mathrm{H}-2^{\prime}, 6^{\prime}\right), 7.03\left(2 \mathrm{H}, \mathrm{d}, J 8.8 \mathrm{~Hz}, \mathrm{H}-3^{\prime \prime}, 5^{\prime \prime}\right), 3.90\left(6 \mathrm{H}, \mathrm{s}, \mathrm{OCH}_{3}-\right.$ $\left.3^{\prime}, 5^{\prime}\right), 3.83\left(3 \mathrm{H}, \mathrm{s}, \mathrm{OCH}_{3}\right), 3.77\left(3 \mathrm{H}, \mathrm{s}, \mathrm{OCH}_{3}\right)$; EIMS m/z $329[\mathrm{M}+1]^{+}(19), 328[\mathrm{M}]^{+}$(100), 327 (13), 314 (12), 313 (59), 297 (29), 285 (20), 195 (31), 171 (12), 161 (65), 133 (44), 118 (22), 109 (14), 89 (27), 77 (35); Anal. Calcd. for $\mathrm{C}_{19} \mathrm{H}_{20} \mathrm{O}_{5}: \mathrm{C}, 69.50 ; \mathrm{H}, 6.14$. Found: $\mathrm{C}, 69.62 ; \mathrm{H}, 6.18$.

(2E)-3-(3-Hydroxy-4-methoxyphenyl)-1-(3,4,5-trimethoxyphenyl)-2-propen-1-one (3ab). Yellow crystals; Yield $4.2 \mathrm{~g}, 61 \%$; mp $126-128{ }^{\circ} \mathrm{C}$ (Lit. $\left.{ }^{39} 127-129{ }^{\circ} \mathrm{C}\right) ;{ }^{1} \mathrm{H}$ NMR (DMSO-d $): \delta 9.19(1 \mathrm{H}, \mathrm{s}, \mathrm{OH}), 7.71(1 \mathrm{H}, \mathrm{d}, J 15.4 \mathrm{~Hz}, \mathrm{H}-$ 2), $7.62(1 \mathrm{H}, \mathrm{d}, J 15.4 \mathrm{~Hz}, \mathrm{H}-3), 7.40\left(2 \mathrm{H}, \mathrm{s}, \mathrm{H}-2^{\prime}, 6^{\prime}\right), 7.39\left(1 \mathrm{H}, \mathrm{d}, J 2 \mathrm{~Hz}, \mathrm{H}-2^{\prime \prime}\right), 7.30(1 \mathrm{H}, \mathrm{dd}, J 8.3 \mathrm{~Hz}, J 2 \mathrm{~Hz}, \mathrm{H}-$ 6"), $7.00\left(1 \mathrm{H}, \mathrm{d}, J 8.3 \mathrm{~Hz}, 5^{\prime \prime}\right), 3.90\left(6 \mathrm{H}, \mathrm{s}, \mathrm{OCH}_{3}-3^{\prime}, 5^{\prime}\right), 3.84\left(3 \mathrm{H}, \mathrm{s}, \mathrm{OCH}_{3}\right), 3.76\left(3 \mathrm{H}, \mathrm{s}, \mathrm{OCH}_{3}\right)$; EIMS m/z 345 $[\mathrm{M}+1]^{+}(21), 344\left[_{\mathrm{M}]^{+}}(100), 330\right.$ (12), 329 (58), 313 (25), 301 (17), 195 (37), 177 (34), 156 (24), 134 (18), 117 (17), 106 (10), 105 (13), 89 (28), 77 (26); Anal. Calcd. for $\mathrm{C}_{19} \mathrm{H}_{20} \mathrm{O}_{6}$ : C, 66.27; H 5.85. Found: C, 66.40; H, 5.88.

(2E)-3-(3-Hydroxy-4-methoxyphenyl)-1-(4-methoxyphenyl)-2-propen-1-one (3bb). The reaction mixture was stirred at room temperature for $72 \mathrm{~h}$. Yellow crystals; Yield $3.18 \mathrm{~g}, 56 \%$; mp 149-151 ${ }^{\circ} \mathrm{C}\left(\right.$ Lit. $\left.^{40} 150-152{ }^{\circ} \mathrm{C}\right) ;{ }^{1} \mathrm{H}$ NMR (DMSO-d $\left.)_{6}\right): \delta 9.10(1 \mathrm{H}, \mathrm{s}, \mathrm{OH}), 8.13\left(2 \mathrm{H}, \mathrm{d}, J 8.7 \mathrm{~Hz}, \mathrm{H}-2^{\prime}, 6^{\prime}\right), 7.69(1 \mathrm{H}, \mathrm{d}, J 15.5 \mathrm{~Hz}, \mathrm{H}-2), 7.59(1 \mathrm{H}, \mathrm{d}, J 15.5$ $\mathrm{Hz}, \mathrm{H}-3), 7.31\left(1 \mathrm{H}, \mathrm{s}, \mathrm{H}-2^{\prime \prime}\right), 7.28\left(1 \mathrm{H}, \mathrm{d}, J 8.3 \mathrm{~Hz}, \mathrm{H}-6^{\prime \prime}\right), 7.07\left(2 \mathrm{H}, \mathrm{d}, J 8.7 \mathrm{~Hz}, \mathrm{H}-3^{\prime}, 5^{\prime}\right), 7.0\left(1 \mathrm{H}, \mathrm{d}, J 8.3 \mathrm{~Hz}, 5^{\prime \prime}\right)$, $3.87\left(3 \mathrm{H}, \mathrm{s}, \mathrm{OCH}_{3}\right), 3.84\left(3 \mathrm{H}, \mathrm{s}, \mathrm{OCH}_{3}\right)$; EIMS m/z $285[\mathrm{M}+1]^{+}$(10), $284[\mathrm{M}]^{+}(51), 283$ (16), 269 (32), 241 (10), 177 (11), 135 (83), 117 (14), 107 (27), 105 (20), 92 (71), 89 (41), 77 (100); Anal. Calcd. for $\mathrm{C}_{17} \mathrm{H}_{16} \mathrm{O}_{4}: \mathrm{C}, 71.82 ; \mathrm{H}$, 5.67. Found: $\mathrm{C}, 71.88 ; \mathrm{H}, 5.70$.

(2E)-1-(3-Hydroxy-4-methoxyphenyl)-3-(4-methoxyphenyl)-2-propen-1-one (3ca). Acetyl group was hydrolyzed during the condensation of 5-acetyl-2-methoxyphenyl acetate (1c) and anisaldehyde (2a) (Scheme 3). Yellow crystals; Yield $3.24 \mathrm{~g}, 57 \%$; mp 106-108 ${ }^{\circ} \mathrm{C} ;{ }^{1} \mathrm{H}$ NMR (DMSO-d $): \delta 9.35(1 \mathrm{H}, \mathrm{s}, \mathrm{OH}), 7.82(2 \mathrm{H}, \mathrm{d}, J 8.7$ Hz, H-2",6"), $7.74(1 \mathrm{H}, \mathrm{d}, J 15.5 \mathrm{~Hz}, \mathrm{H}-2), 7.73(1 \mathrm{H}, \mathrm{dd}, J 8.5 \mathrm{~Hz}, J 2.0 \mathrm{~Hz}, \mathrm{H}-6$ '), 7.65 (1H, d, J $15.5 \mathrm{~Hz}, \mathrm{H}-3), 7.52$ $\left(1 \mathrm{H}, \mathrm{d}, J 2.0 \mathrm{~Hz}, \mathrm{H}-2^{\prime}\right), 7.05\left(1 \mathrm{H}, \mathrm{d}, J 8.5 \mathrm{~Hz}, \mathrm{H}-5^{\prime}\right), 7.01\left(2 \mathrm{H}, \mathrm{d}, J 8.5 \mathrm{~Hz}, \mathrm{H}-3^{\prime \prime}, 5^{\prime \prime}\right), 3.88\left(3 \mathrm{H}, \mathrm{s}, \mathrm{OCH}_{3}\right), 3.82(3 \mathrm{H}, \mathrm{s}$, $\mathrm{OCH}_{3}$ ); EIMS m/z 285 [M+1] ${ }^{+}$(19), $284[\mathrm{M}]^{+}$(100), 283 (23), 269 (53), 253 (20), 161 (46), 151 (37), 133 (25), 108 (19), 89 (24), 77 (25); Anal. Calcd. for $\mathrm{C}_{17} \mathrm{H}_{16} \mathrm{O}_{4}$ : C, 71.82; $\mathrm{H}, 5.67$. Found: $\mathrm{C}, 71.96 ; \mathrm{H}, 5.72 \%$.

(2E)-1-(4-Methoxyphenyl)-3-(3,4,5-trimethoxyphenyl)-2-propen-1-one (3d). Yellow crystals; Yield $4.86 \mathrm{~g}$, 74\%; mp 132-134 ${ }^{\circ} \mathrm{C}$ (Lit. $\left.{ }^{36} 131-133{ }^{\circ} \mathrm{C}\right) ;{ }^{1} \mathrm{H}$ NMR (DMSO-d 6$): \delta 8.18\left(2 \mathrm{H}, \mathrm{d}, J 8.9 \mathrm{~Hz}, \mathrm{H}-2^{\prime}, 6^{\prime}\right), 7.89(1 \mathrm{H}, \mathrm{d}, J 15.5$ $\mathrm{Hz}, \mathrm{H}-2), 7.66(1 \mathrm{H}, \mathrm{d}, J 15.5 \mathrm{~Hz}, \mathrm{H}-3), 7.22\left(2 \mathrm{H}, \mathrm{s}, \mathrm{H}-2^{\prime \prime}, 6^{\prime \prime}\right), 7.10\left(2 \mathrm{H}, \mathrm{d}, J 8.9 \mathrm{~Hz}, \mathrm{H}-3^{\prime}, 5^{\prime}\right), 3.88\left(3 \mathrm{H}, \mathrm{s}, \mathrm{OCH}_{3}\right)$, $3.87\left(6 \mathrm{H}, \mathrm{s}, \mathrm{OCH}_{3}-3^{\prime \prime}, 5^{\prime \prime}\right), 3.72\left(3 \mathrm{H}, \mathrm{s}, \mathrm{OCH}_{3}\right)$; EIMS m/z $329[\mathrm{M}+1]^{+}(19), 328[\mathrm{M}]^{+}$(84), 327 (13), 314 (6), 313 (30), 298 (8), 297 (40), 285 (18), 225 (10), 171 (15), 135 (86), 133 (10), 128 (14), 120 (11), 119 (10), 107 (30), 77 (100); Anal. Calcd. for C, 69.50; $\mathrm{H}, 6.14$. Found: $\mathrm{C}_{19} \mathrm{H}_{20} \mathrm{O}_{5}, \mathrm{C}, 69.59 ; \mathrm{H}, 6.17$.

(2E)-1-(3-Hydroxy-4-methoxyphenyl)-3-(3,4,5-trimethoxyphenyl)-2-propen-1-one (3e). Acetyl group was hydrolyzed during the condensation of 5-acetyl-2-methoxyphenyl acetate (1c) and 3,4,5trimethoxybenzaldehyde. Yellow crystals;Yield $4.34 \mathrm{~g}, 63 \%$; mp $129-131{ }^{\circ} \mathrm{C}$ (Lit. ${ }^{39} 130-132{ }^{\circ} \mathrm{C}$ ); ${ }^{1} \mathrm{H} \mathrm{NMR}$ (DMSO- $\left.d_{6}\right): \delta 9.39(1 \mathrm{H}, \mathrm{s}, \mathrm{OH}), 7.83(1 \mathrm{H}, \mathrm{d}, J 15.5 \mathrm{~Hz}, \mathrm{H}-2), 7.76(1 \mathrm{H}, \mathrm{dd}, J 8.5 \mathrm{~Hz}, J 1.8 \mathrm{~Hz}, \mathrm{H}-6$ '), $7.62(1 \mathrm{H}, \mathrm{d}, J$ $15.4 \mathrm{~Hz}, \mathrm{H}-3), 7.54\left(1 \mathrm{H}, \mathrm{d}, J 1.8 \mathrm{~Hz}, \mathrm{H}-2^{\prime}\right), 7.20\left(2 \mathrm{H}, \mathrm{s}, \mathrm{H}-2^{\prime}\right.$ ',6"), $7.07\left(1 \mathrm{H}, \mathrm{d}, J 8.5 \mathrm{~Hz}, 5\right.$ '), $3.88\left(3 \mathrm{H}, \mathrm{s}, \mathrm{OCH}_{3}\right), 3.87$ $\left(6 \mathrm{H}, \mathrm{s}, \mathrm{OCH}_{3}-3^{\prime \prime}, 5^{\prime \prime}\right), 3.71\left(3 \mathrm{H}, \mathrm{s}, \mathrm{OCH}_{3}\right)$; EIMS m/z $345[\mathrm{M}+1]^{+}$(19), $344[\mathrm{M}]^{+}$(100), 330 (8), 329 (40), 314 (9), 313 (42), 301 (13), 157 (5), 151 (13), 127 (6); Anal. Calcd. for $\mathrm{C}_{19} \mathrm{H}_{20} \mathrm{O}_{6}$ : C, 66.27; H, 5.85. Found: C, 66.37; $\mathrm{H}$, 5.89 .

General procedure for the synthesis of chalcone acetates 3ab-Ac, 3bb-Ac, and 3ca-Ac. The mixture of AcCl $(1.18 \mathrm{~g}, 15 \mathrm{mmol})$ and pyridine $(1.19 \mathrm{~g}, 15 \mathrm{mmol})$ in abs. $\mathrm{CH}_{2} \mathrm{Cl}_{2}(15 \mathrm{~mL})$ was added by small portions to a 
stirred solution of a correcponding chalcone 3 (10 mmol) and pyridine $(0.79 \mathrm{~g}, 10 \mathrm{mmol})$ in abs. $\mathrm{CH}_{2} \mathrm{Cl}_{2}(50 \mathrm{~mL})$ at $20^{\circ} \mathrm{C}$. The reaction mixture was stirred at room temperature for $3 \mathrm{~h}$, diluted with water $(50 \mathrm{~mL})$, and the organic layer was separated. Water layer was extracted by $\mathrm{CH}_{2} \mathrm{Cl}_{2}$ (30 mL). Combined organic extracts were washed with water $(3 \times 50 \mathrm{~mL})$, dried with $\mathrm{Na}_{2} \mathrm{SO}_{4}$ and evaporated. The residue was crystallized from EtOAcpetroleum ether (1:1) and dried to afford chalcone acetates 3a-Ac, 3b-Ac, and 3c-Ac.

2-Methoxy-5-[(1E)-3-oxo-3-(3,4,5-trimethoxyphenyl)-1-propenyl]phenyl acetate (3ab-Ac). Yellow crystals; Yield $2.1 \mathrm{~g}, 72 \%$; mp 114-116 ${ }^{\circ} \mathrm{C} ;{ }^{1} \mathrm{H}$ NMR (DMSO- $\left.d_{6}\right): \delta 7.84(1 \mathrm{H}, \mathrm{d}, J 15.5 \mathrm{~Hz}, \mathrm{H}-2), 7.82\left(1 \mathrm{H}, \mathrm{d}, J 2.2 \mathrm{~Hz}, \mathrm{H}-6{ }^{\prime}\right)$, $7.74\left(1 \mathrm{H}, \mathrm{dd}, J 8.6 \mathrm{~Hz}, J 2.2 \mathrm{~Hz}, \mathrm{H}-4^{\prime}\right), 7.71(1 \mathrm{H}, \mathrm{d}, J 15.5 \mathrm{~Hz}, \mathrm{H}-1), 7.43\left(2 \mathrm{H}, \mathrm{s}, \mathrm{H}-2^{\prime \prime}, 6^{\prime \prime}\right), 7.21(1 \mathrm{H}, \mathrm{d}, J 8.6 \mathrm{~Hz}, \mathrm{H}-$ 3'), $3.91\left(6 \mathrm{H}, \mathrm{s}, \mathrm{OCH}_{3}-3^{\prime \prime}, 5^{\prime \prime}\right), 3.85\left(3 \mathrm{H}, \mathrm{s}, \mathrm{OCH}_{3}\right), 3.77\left(3 \mathrm{H}, \mathrm{s}, \mathrm{OCH}_{3}\right), 2.30\left(3 \mathrm{H}, \mathrm{s}, \mathrm{CH}_{3} \mathrm{C}(\mathrm{O})\right)$; EIMS m/z $386[\mathrm{M}]^{+}$ (15), 344 (28), 329 (21), 313 (9), 301 (7), 195 (18), 177 (15), 156 (13), 89 (12), 77 (16), 43 (100); Anal. Calcd. for $\mathrm{C}_{21} \mathrm{H}_{22} \mathrm{O}_{7}: \mathrm{C}, 65.28 ; \mathrm{H}, 5.74$. Found: $\mathrm{C}, 65.37 ; \mathrm{H}, 5.78$.

2-Methoxy-5-[(1E)-3-(4-methoxyphenyl)-3-oxo-1-propenyl]phenyl acetate (3bb-Ac). Yellow crystals; Yield $0.46 \mathrm{~g}, 81 \% ; \mathrm{mp} 136-138{ }^{\circ} \mathrm{C}$ (EtOAc/petr=1/1); ${ }^{1} \mathrm{H}$ NMR (DMSO-d $\left.d_{6}\right): \delta 8.17\left(2 \mathrm{H}, \mathrm{d}, J 8.9 \mathrm{~Hz}, \mathrm{H}-2^{\prime \prime}, 6^{\prime \prime}\right), 7.85(1 \mathrm{H}$, d, J $15.5 \mathrm{~Hz}, \mathrm{H}-2), 7.79\left(1 \mathrm{H}, \mathrm{d}, J 2.1 \mathrm{~Hz}, \mathrm{H}-6^{\prime}\right), 7.72\left(1 \mathrm{H}, \mathrm{dd}, J 8.6 \mathrm{~Hz}, J 2.1 \mathrm{~Hz}, \mathrm{H}-4{ }^{\prime}\right), 7.66(1 \mathrm{H}, \mathrm{d}, J 15.5 \mathrm{~Hz}, \mathrm{H}-1)$, $7.20\left(1 \mathrm{H}, \mathrm{d}, J 8.6 \mathrm{~Hz}, \mathrm{H}-3^{\prime}\right), 7.08\left(2 \mathrm{H}, \mathrm{d}, J 8.9 \mathrm{~Hz}, \mathrm{H}-3^{\prime \prime}, 5^{\prime \prime}\right), 3.87\left(3 \mathrm{H}, \mathrm{s}, \mathrm{OCH}_{3}\right), 3.84(3 \mathrm{H}, \mathrm{s}, \mathrm{OCH}), 2.30(3 \mathrm{H}, \mathrm{s}$, $\mathrm{CH}_{3} \mathrm{C}(\mathrm{O})$ ); EIMS m/z 326 [M] $^{+}$(6), 284 (14), 269 (9), 135 (22), 92 (13), 77 (25), 43 (100); Anal. Calcd. for $\mathrm{C}_{19} \mathrm{H}_{18} \mathrm{O}_{5}: \mathrm{C}, 69.93 ; \mathrm{H}, 5.56$. Found: $\mathrm{C}, 69.99 ; \mathrm{H}, 5.59$.

2-Methoxy-5-[(2E)-3-(4-methoxyphenyl)-2-propenoyl]phenyl acetate (3ca-Ac). Yellow crystals; Yield 2.9 g, 89\%; mp 126-128 ${ }^{\circ} \mathrm{C} ;{ }^{1} \mathrm{H}$ NMR (DMSO-d $)$ : $\delta 8.13\left(1 \mathrm{H}, \mathrm{dd}, J 8.7 \mathrm{~Hz}, J 2.0 \mathrm{~Hz}, \mathrm{H}-4^{\prime}\right), 7.93\left(1 \mathrm{H}, \mathrm{d}, J 2.0 \mathrm{~Hz}, \mathrm{H}-6^{\prime}\right)$, $7.86\left(2 \mathrm{H}, \mathrm{d}, J 8.7 \mathrm{~Hz}, \mathrm{H}-2^{\prime \prime}, 6^{\prime \prime}\right), 7.81(1 \mathrm{H}, \mathrm{d}, J 15.5 \mathrm{~Hz}, \mathrm{H}-2), 7.71(1 \mathrm{H}, \mathrm{d}, J 15.5 \mathrm{~Hz}, \mathrm{H}-3), 7.30(1 \mathrm{H}, \mathrm{d}, J 8.7 \mathrm{~Hz}, \mathrm{H}-$ 3'), $7.02\left(2 \mathrm{H}, \mathrm{d}, J 8.7 \mathrm{~Hz}, \mathrm{H}-3^{\prime \prime}, 5^{\prime \prime}\right), 3.89\left(3 \mathrm{H}, \mathrm{s}, \mathrm{OCH}_{3}\right), 3.83\left(3 \mathrm{H}, \mathrm{s}, \mathrm{OCH}_{3}\right), 2.31\left(3 \mathrm{H}, \mathrm{s}, \mathrm{CH}_{3} \mathrm{C}(\mathrm{O})\right.$; EIMS m/z 327 $[\mathrm{M}+1]^{+}(16), 326[\mathrm{M}]^{+}(78), 285(20), 284(100), 283(30), 269(43), 253(16), 161(41), 151(21), 133(14), 89(7)$, 77 (8); Anal. Calcd. for $\mathrm{C}_{19} \mathrm{H}_{18} \mathrm{O}_{5}$ : C, 69.93; $\mathrm{H}, 5.56$. Found: $\mathrm{C}, 69.99 ; \mathrm{H}, 5.59$.

3,3-Dimethoxy-2-(4-methoxyphenyl)-1-(3,4,5-trimethoxyphenyl)-1-propanone (4aa). Solution of $\mathrm{H}_{2} \mathrm{SO}_{4}(50 \%$, $5.5 \mathrm{~mL}$ ) in $\mathrm{MeOH}$ was added dropwise to the vigorously stirred suspension of chalcone 3aa $(6.57 \mathrm{~g}, 20 \mathrm{mmol})$ and $\mathrm{PhI}(\mathrm{OAC})_{2}(6.86 \mathrm{~g}, 21.3 \mathrm{mmol})$ in $\mathrm{MeOH}(93 \mathrm{~mL})$ and stirred for $4 \mathrm{~h}$ at room temperature. The reaction solution was diluted with water $(150 \mathrm{~mL})$ and extracted twice by $\mathrm{CH}_{2} \mathrm{Cl}_{2}$ (150 mL and $\left.50 \mathrm{~mL}\right)$. The organic layer was washed with brine, water $(2 \times 50 \mathrm{~mL})$, and dried over anhydrous $\mathrm{Na}_{2} \mathrm{SO}_{4}$. The solvent was evaporated; the remainder oil was diluted with $\mathrm{MeOH}(20 \mathrm{~mL})$, boiled till formation of transparent solution, and kept overnight at 2-6 ${ }^{\circ} \mathrm{C}$. Crystals were filtered, washed with cold EtOH $(2 \times 3 \mathrm{~mL})$, petroleum ether $(3 \mathrm{~mL})$, and dried to afford dimethylacetal 4aa. Colorless crystals; Yield $6.32 \mathrm{~g}, 81 \%$; mp 104-106 ${ }^{\circ} \mathrm{C} ;{ }^{1} \mathrm{H} \mathrm{NMR}\left(\mathrm{CDCl}_{3}\right) \delta 7.32(2 \mathrm{H}, \mathrm{d}$, J $\left.8.3 \mathrm{~Hz}, \mathrm{H}-2^{\prime \prime}, 6^{\prime \prime}\right), 7.26\left(6 \mathrm{H}, \mathrm{s}, \mathrm{H}-2^{\prime}, 6^{\prime}\right), 6.85\left(2 \mathrm{H}, \mathrm{d}, J 8.3 \mathrm{~Hz}, \mathrm{H}-3^{\prime \prime}, 5^{\prime \prime}\right), 5.05(1 \mathrm{H}, \mathrm{d}, J 8.2 \mathrm{~Hz}, \mathrm{H}-2), 4.73(1 \mathrm{H}, \mathrm{d}, J$ $8.2 \mathrm{~Hz}, \mathrm{H}-3), 3.87\left(9 \mathrm{H}, \mathrm{s}, \mathrm{OCH}_{3}-3^{\prime}, 4^{\prime}, 5^{\prime}\right), 3.76\left(3 \mathrm{H}, \mathrm{s}, \mathrm{OCH}_{3}-4^{\prime \prime}\right), 3.46\left(3 \mathrm{H}, \mathrm{s}, \mathrm{OCH}_{3}\right), 3.23\left(3 \mathrm{H}, \mathrm{s}, \mathrm{OCH}_{3}\right) ; \mathrm{EIMS} m / z$ $391[\mathrm{M}+1]^{+}, 390[\mathrm{M}]^{+}$; Anal. Calcd. for $\mathrm{C}_{21} \mathrm{H}_{26} \mathrm{O}_{7}: \mathrm{C}, 64.60 ; \mathrm{H}, 6.71$. Found: $\mathrm{C}, 64.57 ; \mathrm{H}, 6.66$.

General rearrangement procedure for synthesis of dimethylketoacetals $4 \mathrm{ab}, \mathbf{4 b b}$, and $4 \mathrm{ca}$ with simultaneous removal of acetyl group. Solution of $\mathrm{H}_{2} \mathrm{SO}_{4}(50 \%, 5 \mathrm{~mL})$ in $\mathrm{MeOH}$ was added dropwise to the vigorously stirred suspension of chalcone acetate 3ab-Ac, 3bb-Ac, or 3ca-Ac (20 mmol) and Phl(OAc) 2 (30 mmol) in MeOH (100 $\mathrm{mL})$, stirred for $8 \mathrm{~h}$ at room temperature and kept overnight at at 2-6 ${ }^{\circ} \mathrm{C}$. The reaction mixture was diluted with water $(300 \mathrm{~mL})$ and extracted by $\mathrm{CH}_{2} \mathrm{Cl}_{2}(3 \times 100 \mathrm{~mL})$. The organic layer was washed with brine $(2 \times 80$ $\mathrm{mL})$, water $(50 \mathrm{~mL})$, and dried over anhydrous $\mathrm{Na}_{2} \mathrm{SO}_{4}$. The solvent was evaporated; the remainder oil was roughly separated by column chromatography (EtOAc-hexane $=1: 4$ ) to afford $4 \mathbf{a b}$, $\mathbf{4 b}$ b, and 4 ca. $1-(3,4,5-$ Trimethoxyphenyl)-3,3-dimethoxy-2-(3-hydroxy-4-methoxyphenyl)-1-propanone

(4ab) and 1-(4- 
methoxyphenyl)-3,3-dimethoxy-2-(3-hydroxy-4-methoxyphenyl)-1-propanone (4bb) were further used without additional purification.

1-(3-Hydroxy-4-methoxyphenyl)-3,3-dimethoxy-2-(4-methoxyphenyl)-1-propanone (4ca). White solid; Yield $5.82 \mathrm{~g}, 84 \%$; mp $104-107{ }^{\circ} \mathrm{C}$ ( EtOAc/petr); ${ }^{1} \mathrm{H}$ NMR $\left(\mathrm{CDCl}_{3}\right): \delta 7.56(1 \mathrm{H}, \mathrm{dd}, J 8.2 \mathrm{~Hz}, J 2.1 \mathrm{~Hz}, \mathrm{H}-6$ '), $7.55(1 \mathrm{H}, \mathrm{d}$, J $\left.2.1 \mathrm{~Hz}, \mathrm{H}-2^{\prime}\right), 7.32\left(2 \mathrm{H}, \mathrm{d}, J 8.7 \mathrm{~Hz}, \mathrm{H}-2^{\prime \prime}, 6^{\prime \prime}\right), 6.84\left(1 \mathrm{H}, \mathrm{d}, J 8.2 \mathrm{~Hz}, \mathrm{H}-5^{\prime}\right), 6.83\left(2 \mathrm{H}, \mathrm{d}, J 8.7 \mathrm{~Hz}, \mathrm{H}-3^{\prime \prime}, 5^{\prime \prime}\right), 5.61$ $(1 \mathrm{H}, \mathrm{s}, \mathrm{OH}), 5.07(1 \mathrm{H}, \mathrm{d}, J 8.5 \mathrm{~Hz}, \mathrm{H}-2), 4.77(1 \mathrm{H}, \mathrm{d}, J 8.5 \mathrm{~Hz}, \mathrm{H}-3), 3.91\left(3 \mathrm{H}, \mathrm{s}, \mathrm{OCH}_{3}\right), 3.75\left(3 \mathrm{H}, \mathrm{s}, \mathrm{OCH}_{3}\right), 3.43$ $\left(3 \mathrm{H}, \mathrm{s}, \mathrm{OCH}_{3}\right), 3.21\left(3 \mathrm{H}, \mathrm{s}, \mathrm{OCH}_{3}\right)$; EIMS m/z $347[\mathrm{M}+1]^{+}, 346[\mathrm{M}]^{+}$; Anal. Calcd. for $\mathrm{C}_{19} \mathrm{H}_{22} \mathrm{O}_{6}: \mathrm{C}, 65.88 ; \mathrm{H}, 6.40$. Found: $\mathrm{C}, 66.02 ; \mathrm{H}, 6.46$.

2-(4-Methoxyphenyl)-1-(3,4,5-trimethoxyphenyl)ethanone (6). ${ }^{23} \mathrm{KOH}(0.9 \mathrm{~g}, 16 \mathrm{mmol})$ was added to the stirred suspension of dimethylacetal 4aa $(3.12 \mathrm{~g}, 8 \mathrm{mmol})$ in EtOH $(72 \mathrm{~mL})$ and water $(8 \mathrm{~mL})$, and refluxed under argon with stirring for $4 \mathrm{~h}$ (TLC control). The reaction solution was acidified with $\mathrm{HCl}(1 \mathrm{~N})$, evaporated, and diluted with $\mathrm{CH}_{2} \mathrm{Cl}_{2}(150 \mathrm{~mL})$. Organic layer was washed by water $(3 \times 30 \mathrm{~mL})$ and dried over anhydrous $\mathrm{Na}_{2} \mathrm{SO}_{4}$. The solvent was evaporated; the residue was dried in vacuo under $\mathrm{P}_{2} \mathrm{O}_{5}$ at $60-90{ }^{\circ} \mathrm{C}$ to afford 6. White solid; Yield $2.53 \mathrm{~g}, 100 \%$; mp $85-87{ }^{\circ} \mathrm{C}\left(\mathrm{Lit}^{41} 86-88{ }^{\circ} \mathrm{C}\right) ;{ }^{1} \mathrm{H}$ NMR $\left(\mathrm{CDCl}_{3}\right): \delta 7.29\left(2 \mathrm{H}, \mathrm{s}, \mathrm{H}-2^{\prime}, 6^{\prime}\right), 7.18(2 \mathrm{H}, \mathrm{d}, J$ $\left.8.1 \mathrm{~Hz}, \mathrm{H}-2^{\prime \prime}, 6^{\prime \prime}\right), 6.87\left(2 \mathrm{H}, \mathrm{d}, \mathrm{J} 8.1 \mathrm{~Hz}, \mathrm{H}-3^{\prime \prime}, 5^{\prime \prime}\right), 4,19\left(2 \mathrm{H}, \mathrm{s}, \mathrm{CH}_{2}\right), 3.90\left(3 \mathrm{H}, \mathrm{s}, \mathrm{OCH}_{3}\right), 3.89\left(6 \mathrm{H}, \mathrm{s}, \mathrm{OCH}_{3}-3^{\prime}, 5^{\prime}\right)$, $3.79\left(3 \mathrm{H}, \mathrm{s}, \mathrm{OCH}_{3}\right)$; EIMS m/z 316 [M] (8), 196 (16), 195 (100), 167 (5), 152 (11), 137 (12), 135 (8), 122 (11), 121 (45), 109 (10), 98 (8), 81 (15), 78 (22), 77 (26); Anal. Calcd. for $\mathrm{C}_{18} \mathrm{H}_{20} \mathrm{O}_{5}$ : C, 68.34; H, 6.37. Found: C, 68.40; $\mathrm{H}, 6.41$.

5-(4-Methoxyphenyl)-4-(3,4,5-trimethoxyphenyl)-2(3H)-pyrimidinone (7). The mixture of dimethylacetal 4aa $(0.39 \mathrm{~g}, 1 \mathrm{mmol})$, urea $(0.09 \mathrm{~g}, 1.5 \mathrm{mmol})$, and $\mathrm{HCl}(36 \%, 10$ drops) in $\mathrm{EtOH}(2 \mathrm{~mL})$ was refluxed for $6.5 \mathrm{~h}$, and then evaporated to dryness. The deposit was triturated with EtOAc $(1 \mathrm{~mL})$, filtered and dried in vacuo at $60{ }^{\circ} \mathrm{C}$ to afford hydrochloride of 7 as bright yellow crystals $\left(0.27 \mathrm{~g}, 66 \%\right.$; mp $\left.150-160{ }^{\circ} \mathrm{C}\right)$. The crystals were triturated with $\mathrm{NH}_{4} \mathrm{OH}(12 \%)$, washed with water and dried in vacuo under $\mathrm{P}_{2} \mathrm{O}_{5}$ to afford targeted pyrimidinone 7. Yellowish crystals; Yield $0.125 \mathrm{~g}, 34 \%$; mp 131-133 dec. $^{\circ} \mathrm{C} ;{ }^{1} \mathrm{H}$ NMR (DMSO- $\left.d_{6}\right): \delta 13.0(1 \mathrm{H}, \mathrm{br}$, $\mathrm{NH}), 8.16(1 \mathrm{H}, \mathrm{s}, \mathrm{H}-6), 7.06\left(2 \mathrm{H}, \mathrm{d}, J 8.4 \mathrm{~Hz}, \mathrm{H}-2^{\prime \prime}, 6^{\prime \prime}\right), 6.88\left(2 \mathrm{H}, \mathrm{d}, J 8.4 \mathrm{~Hz}, \mathrm{H}-3^{\prime \prime}, 5^{\prime \prime}\right), 6.71\left(2 \mathrm{H}, \mathrm{s}, \mathrm{H}-2^{\prime}, 6^{\prime}\right), 3.87$ $\left(3 \mathrm{H}, \mathrm{s}, \mathrm{OCH}_{3}\right), 3.81\left(3 \mathrm{H}, \mathrm{s}, \mathrm{OCH}_{3}\right), 3.65\left(6 \mathrm{H}, \mathrm{s}, \mathrm{OCH}_{3}-3^{\prime}, 5^{\prime}\right)$; EIMS m/z $369[\mathrm{M}+1]^{+}(21), 368[\mathrm{M}]^{+}(100), 367$ (53), 353 (10), 337 (20), 326 (11), 135 (11), 77 (7); Anal. Calcd. for $\mathrm{C}_{20} \mathrm{H}_{20} \mathrm{~N}_{2} \mathrm{O}_{5}$ : C, 65.21; H, 5.47; N, 7.60. Found: C, $65.33 ; \mathrm{H}, 5.51 ; \mathrm{N}, 7.50$.

6-(4-Methoxyphenyl)-7-(3,4,5-trimethoxyphenyl)pyrazolo[1,5-a]pyrimidine (8). The mixture of dimethylacetal 4aa (0.39 g, $1 \mathrm{mmol})$, 3-aminopyrazole $(0.125 \mathrm{~g}, 1.5 \mathrm{mmol})$ and $\mathrm{HCl}(36 \%, 4 \mathrm{drops})$ in EtOH (1.6 $\mathrm{mL}$ ) was refluxed for $2 \mathrm{~h}$ (TLC control), then evaporated to dryness. The deposit was triturated with $\mathrm{NH}_{4} \mathrm{OH}$ (12\%), filtered, washed with water, $\mathrm{EtOH}(3 \times 0.4 \mathrm{~mL})$, and dried in vacuo at $60^{\circ} \mathrm{C}$ to afford pyrimidinone 8 .

Yellowish crystalls; Yield $0.18 \mathrm{~g}, 45 \%$; $\mathrm{mp} 165-167{ }^{\circ} \mathrm{C}(\mathrm{EtOH}) ;{ }^{1} \mathrm{H}$ NMR (DMSO- $\left.d_{6}\right): \delta 8.61(1 \mathrm{H}, \mathrm{s}, \mathrm{H}-5), 8.20(1 \mathrm{H}$, d, J $2.2 \mathrm{~Hz}, \mathrm{H}-2), 7.21\left(2 \mathrm{H}, \mathrm{d}, J 8.6 \mathrm{~Hz}, \mathrm{H}-2^{\prime}, 6^{\prime}\right), 6.91\left(2 \mathrm{H}, \mathrm{d}, J 8.6 \mathrm{~Hz}, \mathrm{H}-3^{\prime}, 5^{\prime}\right), 6.84(1 \mathrm{H}, \mathrm{d}, J 2.2 \mathrm{~Hz}, \mathrm{H}-3), 6.80(2 \mathrm{H}$, s, H-2",6"), $3.74\left(3 \mathrm{H}, \mathrm{s}, \mathrm{OCH}_{3}\right), 3.70\left(3 \mathrm{H}, \mathrm{s}, \mathrm{OCH}_{3}\right), 3.59\left(6 \mathrm{H}, \mathrm{s}, \mathrm{OCH}_{3}-3^{\prime \prime}, 5^{\prime \prime}\right) ; \mathrm{EIMS} \mathrm{m/z} 392[\mathrm{M}+1]^{+}(24), 391$ $\left[\mathrm{M}^{+}(100), 390\right.$ (53), 344 (11), 290 (11), 262 (11), 219 (19), 218 (15), 192 (10), 180 (11), 165 (11), $164(16), 152$ (10), 151 (11), 139 (10), 126 (10), 89 (14), 77 (11); Anal. Calcd. for $\mathrm{C}_{22} \mathrm{H}_{21} \mathrm{~N}_{3} \mathrm{O}_{4}$ : C, 67.51; H, 5.41; N, 10.74. Found: $\mathrm{C}, 67.60 ; \mathrm{H}, 5.45 ; \mathrm{N}, 10.67 \%$.

6-(4-Methoxyphenyl)-7-(3,4,5-trimethoxyphenyl)[1,2,4]triazolo[1,5-a]pyrimidine (9aa). The mixture of dimethylacetal 4aa (0.39 g, $1 \mathrm{mmol})$, 3-amino-1,2,4-triazole $(0.125 \mathrm{~g}, 1.5 \mathrm{mmol})$, and $\mathrm{HCl}(36 \%, 4 \mathrm{drops})$ in $\mathrm{EtOH}(1.6 \mathrm{~mL})$ was refluxed for $3 \mathrm{~h}$ (TLC control), then evaporated to dryness. The deposit was triturated with abs. ether $(1 \mathrm{~mL})$, filtered and dried in vacuo to afford hydrochloride of 9aa as yellow crystals $(0.28 \mathrm{~g}, 66 \%)$. Hydrochloride of 9aa was triturated with $\mathrm{NH}_{4} \mathrm{OH}(12 \%)$, filtered, washed with water and dried in vacuo at 60 
${ }^{\circ} \mathrm{C}$ to afford pyrimidinone 9aa. White powder; Yield $0.24 \mathrm{~g}, 61 \%$; mp 190-192 ${ }^{\circ} \mathrm{C} ;{ }^{1} \mathrm{H}$ NMR (DMSO- $\left.d_{6}\right): \delta 8.94$ $\left(1 \mathrm{H}, \mathrm{s}, \mathrm{H}-2,8.66(1 \mathrm{H}, \mathrm{s}, \mathrm{H}-5), 7.24\left(2 \mathrm{H}, \mathrm{d}, J 8.7 \mathrm{~Hz}, \mathrm{H}-2^{\prime}, 6^{\prime}\right), 6.95\left(2 \mathrm{H}, \mathrm{d}, J 8.7 \mathrm{~Hz}, \mathrm{H}-3^{\prime}, 5^{\prime}\right), 6.85\left(2 \mathrm{H}, \mathrm{s}, \mathrm{H}-2^{\prime \prime}, 6^{\prime \prime}\right)\right.$, $3.76\left(3 \mathrm{H}, \mathrm{s}, \mathrm{OCH}_{3}\right), 3.71\left(3 \mathrm{H}, \mathrm{s}, \mathrm{OCH}_{3}\right), 3.60\left(6 \mathrm{H}, \mathrm{s}, \mathrm{OCH}_{3}-3^{\prime \prime}, 5^{\prime \prime}\right) ; \mathrm{EIMS} \mathrm{m/z} 393[\mathrm{M}+1]^{+}(20), 392[\mathrm{M}]^{+}(100), 391$ (22), 377 (18), 361 (10), 346 (10), 317 (16), 275 (16), 274 (12), 221 (10), 220 (12), 195 (16), 193 (13), 181 (9), 180 (13), 166 (10), 165 (13), 164 (11), 151 (11), 139 (10), 89 (7), 77 (7); Anal. Calcd. for $\mathrm{C}_{21} \mathrm{H}_{20} \mathrm{~N}_{4} \mathrm{O}_{4}:$ C, 64.28; H, $5.14 ; \mathrm{N}, 14.28$. Found: $C, 64.33 ; H, 5.17 ; \mathrm{N}, 14.21$.

General procedure for synthesis of triazolopyrimidines 9ab, 9bb, and 9ca from crude ketoacetals 4ab, 4bb, and $4 \mathbf{c a}$. The mixture of dimethylacetal $4 \mathbf{a b}, \mathbf{4 b b}$, or $4 \mathrm{ca}$ (3.65 mmol), 3-amino-1,2,4-triazole $(0.31 \mathrm{~g}, 3.65$ $\mathrm{mmol})$ and $\mathrm{HCl}\left(36 \%, 10\right.$ drops) in $\mathrm{EtOH}(10 \mathrm{~mL})$ was refluxed for $5 \mathrm{~h}$ and kept overnight at 2-6 ${ }^{\circ} \mathrm{C}$. The deposit was filtered and washed with hot EtOAc $(3 \times 10 \mathrm{~mL})$ to afford hydrochlorides of triazolopyrimidines 9ab, 9bb, and $9 \mathrm{ca}$. Then they were stirred with $\mathrm{NH}_{4} \mathrm{OH}(20 \%, 10 \mathrm{~mL})$, filtered, reprecipitated from DMF by EtOH, and dried to afford targeted pyrimidinones $9 \mathrm{ab}, \mathbf{9 b b}$, and $9 \mathrm{ca}$.

6-(3-Hydroxy-4-methoxyphenyl)-7-(3,4,5-trimethoxyphenyl)[1,2,4]triazolo[1,5-a]pyrimidine (9ab). White crystals; Yield $0.94 \mathrm{~g}, 63 \%$; mp 228-232 ${ }^{\circ} \mathrm{C}$; (9ab-hydrochloride: mp 161-164dec. ${ }^{\circ} \mathrm{C}$ ); ${ }^{1} \mathrm{H}$ NMR (DMSO- $\left.d_{6}\right): \delta 9.05$ $(1 \mathrm{H}, \mathrm{br}, \mathrm{OH}), 8.90(1 \mathrm{H}, \mathrm{s}, \mathrm{H}-2), 8.64(1 \mathrm{H}, \mathrm{s}, \mathrm{H}-5), 6.93\left(1 \mathrm{H}, \mathrm{d}, \mathrm{J} 8.2 \mathrm{~Hz}, \mathrm{H}-5^{\prime}\right), 6.87\left(2 \mathrm{H}, \mathrm{s}, \mathrm{H}-2^{\prime \prime}, 6^{\prime \prime}\right), 6.73$ (1H, dd, J $\left.8.2 \mathrm{~Hz}, J 2.0 \mathrm{~Hz}, \mathrm{H}-6^{\prime}\right), 6.71\left(1 \mathrm{H}, \mathrm{d}, J 2.0 \mathrm{~Hz}, \mathrm{H}-2^{\prime}\right), 3.76\left(3 \mathrm{H}, \mathrm{s}, \mathrm{OCH}_{3}\right), 3.72\left(3 \mathrm{H}, \mathrm{s}, \mathrm{OCH}_{3}\right), 3.61\left(2 \mathrm{H}, \mathrm{s}, \mathrm{H}-3^{\prime \prime}, 5^{\prime \prime}\right)$; EIMS m/z $409[\mathrm{M}+1]^{+}(22), 408[\mathrm{M}]^{+}(100), 407$ (6), 378 (6), 329 (9), 188 (10), 173 (8), 165 (9), 151 (8), 127 (9), 84 (49); Anal. Calcd. for $\mathrm{C}_{21} \mathrm{H}_{20} \mathrm{~N}_{4} \mathrm{O}_{5}: \mathrm{C}, 61.76 ; \mathrm{H}, 4.94 ; \mathrm{N}, 13.72$. Found: $\mathrm{C}, 61.78 ; \mathrm{H}, 4.98 ; \mathrm{N}, 13.62 \%$.

6-(3-Hydroxy-4-methoxyphenyl)-7-(4-methoxyphenyl)[1,2,4]triazolo[1,5-a]pyrimidine (9bb). White crystals; Yield $0.83 \mathrm{~g}, 65 \%$; mp 258-260 ${ }^{\circ} \mathrm{C} ;{ }^{1} \mathrm{H}$ NMR (DMSO-d $): \delta 9.07(1 \mathrm{H}, \mathrm{s}, \mathrm{OH}), 8.86(1 \mathrm{H}, \mathrm{s}, \mathrm{H}-2), 8.61(1 \mathrm{H}, \mathrm{s}, \mathrm{H}-5)$, $7.47\left(2 \mathrm{H}, \mathrm{d}, J 8.7 \mathrm{~Hz}, \mathrm{H}-2^{\prime \prime}, 6^{\prime \prime}\right), 6.99\left(2 \mathrm{H}, \mathrm{d}, J 8.7 \mathrm{~Hz}, \mathrm{H}-3^{\prime \prime}, 5^{\prime \prime}\right), 6.90\left(1 \mathrm{H}, \mathrm{d}, J 7.9 \mathrm{~Hz}, \mathrm{H}-5^{\prime}\right), 6.69\left(1 \mathrm{H}, \mathrm{s}, \mathrm{H}-2^{\prime}\right), 6.68$ $\left(1 \mathrm{H}, \mathrm{d}, J 7.9 \mathrm{~Hz}, \mathrm{H}-6^{\prime}\right), 3.80\left(3 \mathrm{H}, \mathrm{s}, \mathrm{OCH}_{3}\right), 3.76\left(3 \mathrm{H}, \mathrm{s}, \mathrm{OCH}_{3}\right) ; \operatorname{EIMS} \mathrm{m} / z 349[\mathrm{M}+1]^{+}(21), 348[\mathrm{M}]^{+}(100), 347$ (77), 333 (6), 332 (9), 305 (8), 152 (11), 135 (17), 92 (13), 77 (20); Anal. Calcd. for $\mathrm{C}_{19} \mathrm{H}_{16} \mathrm{~N}_{4} \mathrm{O}_{3}$ : C, 65.51; H, 4.63; $\mathrm{N}, 16.08$. Found: $C, 65.58 ; \mathrm{H}, 4.66 ; \mathrm{N}, 16.02$.

7-(3-Hydroxy-4-methoxyphenyl)-6-(4-methoxyphenyl)[1,2,4]triazolo[1,5-a]pyrimidine (9ca). White crystals; Yield $0.3 \mathrm{~g}, 24 \%$; mp 278-282 ${ }^{\circ} \mathrm{C} ;{ }^{1} \mathrm{H}$ NMR (DMSO-d $\left.)\right): \delta 9.22(1 \mathrm{H}, \mathrm{s}, \mathrm{OH}), 8.89(1 \mathrm{H}, \mathrm{s}, \mathrm{H}-2), 8.61(1 \mathrm{H}, \mathrm{s}, \mathrm{H}-5)$, $7.22\left(2 \mathrm{H}, \mathrm{d}, J 8.7 \mathrm{~Hz}, \mathrm{H}-2^{\prime}, 6^{\prime}\right), 6.99\left(1 \mathrm{H}, \mathrm{d}, J 2.1 \mathrm{~Hz}, \mathrm{H}-2^{\prime}\right), 6.95\left(1 \mathrm{H}, \mathrm{d}, J 8.4 \mathrm{~Hz}, \mathrm{H}-5^{\prime}\right), 6.92(2 \mathrm{H}, \mathrm{d}, J 8.7 \mathrm{~Hz}, \mathrm{H}-$ $\left.3^{\prime}, 5^{\prime}\right), 6.85\left(1 \mathrm{H}, \mathrm{dd}, J 8.4 \mathrm{~Hz}, J 2.1 \mathrm{~Hz}, \mathrm{H}-6^{\prime}\right), 3.80\left(3 \mathrm{H}, \mathrm{s}, \mathrm{OCH}_{3}\right), 3.76\left(3 \mathrm{H}, \mathrm{s}, \mathrm{OCH}_{3}\right)$; ElMS m/z $349[\mathrm{M}+1]^{+}(17)$, 348 [M] ${ }^{+}$(100), 347 (71), 315 (10), 304 (5), 164 (10), 152 (12), 139 (.9). Anal. Calcd. for $\mathrm{C}_{19} \mathrm{H}_{16} \mathrm{~N}_{4} \mathrm{O}_{3}: \mathrm{C}, 65.51 ; \mathrm{H}$, 4.63; N, 16.08. Found: C, 65.55; H, 4.68; N, 16.03 .

Phenotypic sea urchin embryo assay. ${ }^{34}$ Adult sea urchins, Paracentrotus lividus L. (Echinidae), were collected from the Mediterranean Sea on the Cyprus coast and kept in an aerated seawater tank. Gametes were obtained by intracoelomic injection of $0.5 \mathrm{M} \mathrm{KCl}$. Eggs were washed with filtered seawater and fertilized by adding drops of diluted sperm. Embryos were cultured at room temperature under gentle agitation with a motor-driven plastic paddle $(60 \mathrm{rpm})$ in filtered seawater. The embryos were observed with a Biolam light microscope (LOMO, St. Petersburg, Russia). For treatment with the test compounds, $5 \mathrm{~mL}$ aliquots of embryo suspension were transferred to six-well plates and incubated as a monolayer at a concentration up to 2000 embryos/mL. Stock solutions of compounds were prepared in DMSO at $10 \mathrm{mM}$ concentration followed by a 10 -fold dilution with $96 \% \mathrm{EtOH}$. This procedure enhanced the solubility of the test compounds in the saltcontaining medium (seawater), as evidenced by microscopic examination of the samples. The maximal tolerated concentrations of DMSO and $\mathrm{EtOH}$ in the in vivo assay were determined to be $0.05 \%$ and $1 \%$, 
respectively. Higher concentrations of either DMSO (>0.1\%) or EtOH $(>1 \%)$ caused nonspecific alteration and retardation of the sea urchin embryo development independent of the treatment stage. Combretastatin A-4 (synthesized as reported previously ${ }^{42}$ ) served as a positive control. The antiproliferative activity was assessed by exposing fertilized eggs (8-15 min after fertilization, 45-55 min before the first mitotic cycle completion) to 2 -fold decreasing concentrations of the compound. Cleavage alteration and arrest were clearly detected at 2.5-5.5 h after fertilization, when control embryos reached 8-cell and early blastula stages, respectively. The effects were estimated quantitatively as an effective threshold concentration, resulting in cleavage alteration and embryo death before hatching or full mitotic arrest. At these concentrations all tested microtubule destabilizers caused $100 \%$ cleavage alteration and embryo death before hatching, whereas at 2-fold lower concentrations the compounds failed to produce any effect. For microtubule-destabilizing activity, the compounds were tested on free-swimming blastulae just after hatching (8-10 h after fertilization), which originated from the same embryo culture. Embryo spinning was observed after $15 \mathrm{~min}$ to $20 \mathrm{~h}$ of treatment, depending on the structure and concentration of the compound. Both spinning and lack of forward movement were interpreted to be the result of the microtubule-destabilizing activity of a molecule. Video illustrations are available at http://www.chemblock.com. Both sea urchin embryo assay and DTP NCI60 cell line activity data are available free of charge via the Internet at http://www.zelinsky.ru. Experiments with the sea urchin embryos fulfill the requirements of biological ethics. The artificial spawning does not cause animal death, embryos develop outside the female organism, and both post spawned adult sea urchins and the excess of intact embryos are returned to the sea, their natural habitat.

\section{Acknowledgements}

The authors thank Dr. Ju. A. Strelenko from N. D. Zelinsky Institute of Organic Chemistry RAS for the development a software for NMR spectra presentation.

\section{References}

1. Habib, N. S.; Soliman, R.; El-Tombary, A. A.; El-Hawash, S. A.; Shaaban, O. G. Arch. Pharm. Res. 2007, 30, 1511.

https://doi.org/10.1007/BF02977319

2. Bazgira, A.; Khanaposhtani, M. M.; Soorki, A. A. Bioorg. Med. Chem. Lett. 2008, 18, 5800. https://doi.org/10.1016/i.bmcl.2008.09.057

3. Johar, M.; Manning, T.; Kunimoto, D. Y.; Kumara, R. Bioorg. Med. Chem. 2005, 13, 6663. https://doi.org/10.1016/j.bmc.2005.07.046

4. Fathalla, O. A.; Awad, S. M.; Mohamed, M. S. Arch. Pharm. Res. 2005, 28, 1205. https://doi.org/10.1007/BF02978199

5. Cosimelli, B.; Greco, G.; Ehlardo, M.; Novellino, E.; Da Settimo, F.; Taliani, S.; La Motta, C.; Bellandi, M.; Tuccinardi, T.; Martinelli, A.; Ciampi, O.; Trincavelli, M. L.; Martini, C. J. Med. Chem. 2008, 51, 1764. https://doi.org/10.1021/jm701159t

6. Li, J.; Zhao, Y. F.; Zhao, X. L.; Yuan, X. Y.; Gong, P. Arch. Pharm. Chem. Life Sci. 2006, 339, 593. https://doi.org/10.1002/ardp.200600098 
7. Shallal, H. M.; Russu, W. A. Eur. J. Med. Chem. 2011, 46, 2043.

https://doi.org/10.1016/j.ejmech.2011.02.057

8. Rostom, S. A. F.; Badr, M. H.; Abd El Razik, H. A.; Ashour, H. M. A.; Abd El Wahab, A. E. Arch. Pharm. Chem. Life Sci. 2011, 344, 572.

https://doi.org/10.1002/ardp.201100077

9. Pettit, G. R.; Singh, S. B.; Hamel, E.; Lin, C. M.; Alberts, D. S.; Garcia-Kendall, D. Experientia 1989, 45, 209. https://doi.org/10.1007/BF01954881

10. Tron, G. C.; Pyrali, T.; Sorba, G.; Pagliai, F.; Busacca, S.; Genazzani, A. A. J. Med. Chem. 2006, 49, 3033. https://doi.org/10.1021/jm0512903

11. Ohsumi, K.; Hatanaka, T.; Fujita, K.; Nakagawa, R.; Fukuda, Y.; Nihei, Y.; Suga, Y.; Morinaga, Y.; Akiyama, Y.; Tsuji, T. Bioorg. Med. Chem. Lett. 1998, 8, 3153.

https://doi.org/10.1016/S0960-894X(98)00579-4

12. Bonezzi, K.; Taraboletti, G.; Borsotti, P.; Bellina, F.; Rossi, R.; Giavazzi, R. J. Med. Chem. 2009, $52,7906$. https://doi.org/10.1021/jm900968s

13. Kaffy, J.; Pontikis, R.; Carrez, D.; Croisy, A.; Monneret, C.; Florent, J. C. Bioorg. Med. Chem. 2006, 14, 4067. https://doi.org/10.1016/i.bmc.2006.02.001

14. Lee, S.; Kim, J. N.; Lee, H. K.; Yoon, K. S.; Shin, K. D.; Kwon, B. M.; Han, D. C. Bioorg. Med. Chem. Lett. 2011, 21, 977.

\section{https://doi.org/10.1016/j.bmcl.2010.12.044}

15. Wu, M.; Sun, Q.; Yang, C.; Chen, D.; Ding, J.; Chen, Y.; Lin, L.; Xie, Y. Bioorg. Med. Chem. Lett. 2007, $17,869$. https://doi.org/10.1016/j.bmcl.2006.11.060

16. Romagnoli, R.; Baraldi, P. G.; Cruz-Lopez, O.; Lopez Cara, C.; Carrion, M. D.; Brancale, A.; Hamel, E.; Chen, L.; Bortolozzi, R.; Basso, G.; Viola, G. J. Med. Chem. 2010, 53, 4248.

https://doi.org/10.1021/jm100245q

17. Demchuk, D. V.; Samet, A. V.; Chernysheva, N. B.; Ushkarov, V. I.; Stashina, G. A.; Konyushkin, L. D.; Raihstat, M. M.; Firgang, S. I.; Philchenkov, A. A.; Zavelevich, M. P.; Kuiava, L. M.; Chekhun, V. F.; Blokhin, D. Yu.; Kiselyov, A. S.; Semenova, M. N.; Semenov V. V. Bioorg. Med. Chem. 2014, 22, 738. https://doi.org/10.1016/j.bmc.2013.12.015

18. Beale, T. M.; Allwood, D. M.; Bender, A.; Bond, P. J.; Brenton, J. D.; Charnock-Jones, D. S.; Ley, D. V.; Myers, R. M.; Shearman, J. W.; Temple, J.; Unger, J.; Watts, C. A.; Xian, J. ACS Med. Chem. Lett. 2012, 3, 177. https://doi.org/10.1021/ml200149g

19. Romagnoli, R.; Baraldi, P. G.; Salvador, M. K.; Preti, D.; Tabrizi, M. A.; Brancale, A.; Fu, X. H.; Li, J.; Zhang, S. Z.; Hamel, E.; Bortolozzi, R.; Basso, G.; Viola, G. J. Med. Chem. 2012, 55, 475.

https://doi.org/10.1021/jm2013979

20. Jedhe, G. S.; Paul, D.; Gonnade, R. G.; Santra, M. K.; Hamel, E.; Nguyen, T. L.; Sanjayan, G. J. Bioorg. Med. Chem. Lett. 2013, 23, 4680.

https://doi.org/10.1016/j.bmcl.2013.06.004

21. Schmitt, M. R.; Kirsch, D. R.; Harris, J. E.; Beyer, C. F.; Pees, K.-J.; Carter, P. A.; Pfrengle, W.; Albert, G. U.S. Patent 20020068744, 2002.

22. Yusubov, M. S.; Zholobova, G. A.; Filimonova, I. L.; Chi, K. W. Russ. Chem. Bull. 2004, 53, 1735; Izvestiya Akademii Nauk, Seriya Khimicheskaya 2004, 53, 1669.

23. Vu, B.; Mezey-Vandor, G.; Nogradi, M. Liebigs Ann. Chem. 1984, 4, 734.

https://doi.org/10.1002/jlac.198419840410 
24. Coulthard, E. C.; Marshall, J.; Pyman, F. L. J. Chem. Soc. 1930, 280.

https://doi.org/10.1039/JR9300000280

25. Petrov; A. A.; Kasatochkin, A. N. Russ. J. Org. Chem. 2013, 49, 502.

26. Allen, C. F. H.; Beilfuss, H. R.; Burness, D. M.; Reynolds, G. A.; Tinker, J. F.; VanAllan, J. A. J. Org. Chem. 1959, 24, 787.

https://doi.org/10.1021/jo01088a014

27. Sirakawa, K. Yakugaku Zasshi 1959, 79, 1487.

https://doi.org/10.1248/yakushi1947.79.12 1487

28. Cook, J. W.; Gentles, R. P.; Tucker, S. H. Recl. Trav. Chim. Pay-B. 1950, 69, 343.

https://doi.org/10.1002/recl.19500690314

29. Cox, J. M.; Chu, H. D.; Kuethe, J. T.; Gao, Y.-D.; Scapin, G.; Eiermann, G.; He, H.; Li, X.; Lyons, K. A.; Metzger, J.; Petrov, A.; Wu, J. K.; Xu, S.; Sinha-Roy, R.; Weber, A. E.; Biftu, T. Bioorg. Med. Chem. Lett. 2016, $26,2622$. https://doi.org/10.1016/i.bmcl.2016.04.020

30. Zhang, Z.-T.; Xie, J.; Zhu, M.-L.; Xue, D. Synlett 2010, 12, 1825.

https://doi.org/10.1055/s-0030-1258105

31. Sheldrick, G. M. SADABS, v. 2.03, Bruker/Siemens Area Detector Absorption Correction Program, Bruker AXS, Madison, Wisconsin, 2003.

32. Sheldrick, G. M. Acta Cryst. 2015, C71, 3.

33. Fax: +44 1223 336033; e-mail: deposit@ccdc.cam.ac.uk or www.ccdc.cam.ac.uk.

34. Semenova, M. N.; Kiselyov, A. S.; Semenov, V. V. BioTechniques 2006, 40, 765.

https://doi.org/10.2144/000112193

35. Semenov, V. V.; Semenova, M. N. Russ. Chem. Rev. 2015, 84, 134.

https://doi.org/10.1070/RCR4449

36. Ducki, S.; Rennison, D.; Woo, M.; Kendall, A.; Chabert, J. F. D.; McGown, A. T.; Lawrence, N. J. Bioorg. Med. Chem. 2009, 17, 7698.

https://doi.org/10.1016/j.bmc.2009.09.039

37. Saxena, H. O.; Faridi, U.; Srivastava, S.; Kumar, J. K.; Darokar, M. P.; Luqman, S.; Chanotiya, C. S.; Krishna, V.; Negi, A. S.; Khanuja, S. P. S. Bioorg. Med. Chem. Lett. 2008, 18, 3914.

https://doi.org/10.1016/j.bmcl.2008.06.039

38. Gutsche, C. D.; Jason, E. F.; Coffey, R. S.; Johnson, H. E. J. Am. Chem. Soc. 1958, 80, 5756. https://doi.org/10.1021/ja01554a043

39. Kong, Y.; Wang, K.; Edler, M. C.; Hamel, E.; Mooberry, S. L.; Paige, M. A.; Brown, M. L. Bioorg. Med. Chem. 2010, 18, 971.

https://doi.org/10.1016/j.bmc.2009.11.003

40. Raghavan, S.; Manogaran, P.; Kuppuswami, B. K.; Venkatraman, G.; Narasimha, K. K. G. Med. Chem. Res. 2015, 24, 4157.

https://doi.org/10.1007/s00044-015-1453-2

41. Acharya, A.; Kumar, S. V.; Ila, H. Chem.Eur. J. 2015, 21, 17116.

https://doi.org/10.1002/chem.201501828

42. Semenov, V. V.; Kiselyov, A. S.; Titov, I. Y.; Sagamanova, I. K.; Ikizalp, N.; Chernysheva, N. B.; Tsyganov, D. V.; Konyushkin, L. D.; Firgang, S. I.; Semenov, R. V.; Karmanova, I. B.; Semenova, M. N. J. Nat. Prod. 2010, 73, 1796.

https://doi.org/10.1021/np100427 